\title{
Mercosul
}

\section{Uma breve análise de suas origens à crise atual}

\author{
Franklin Trein ${ }^{l}$
}

\section{Origem}

O Tratado de Assunção, assinado pela Argentina, Brasil, Paraguai e Uruguai em 26 de março de 1991, deu início ao processo de integração dos países do Cone Sul do continente americano. O Mercado Comum do Sul (Mercosul) como foi denominado, resultou na experiência de integração que apresentou melhores resultados na região. Se compararmos ainda os seus feitos com outros processos de integração em curso no mundo, inclusive com a União Européia, veremos que o êxito do Mercosul, de fato, tem sido considerável e, dadas as condições adversas, até mesmo surpreendente.

O propósito de criação do Mercosul teve sua origem em um passado não muito remoto, nem por isto menos expressivo, de uma radical modificação das respectivas percepções de suas relações bilaterais e multilaterais por parte da Argentina e do Brasil. Pretensões de hegemonia regional, rivalidades históricas e animosidades permanentes deram lugar ao diálogo franco e à disposição de cooperação. Pode-se dizer que nos primeiros momentos os objetivos políticos de aproximação entre os dois países estiveram claramente à frente das motivações econômicas. No entanto, agregar interesses econômicos aos políticos, em um processo de integração, era uma receita que já havia sido experimentada pelos europeus no final

1 Doutor (1977) e Pós-doutor (1984) em filosofia pela Universidade Livre de Berlim e pela Universidade de Estrasburgo respectivamente. Professor da Universidade Federal do Rio de Janeiro, da Universidade de la República e da Universidade Livre de Berlim. 
dos anos 50 através do Tratado de Roma. Assim foi feito também no caso do Mercosul.

A redemocratização dos dois países, ao longo da década de 80 , permitiu que os presidentes José Sarney, do Brasil, e Raul Alfonsín, da Argentina, pudessem estabelecer um diálogo que significava, ao mesmo tempo, o abandono das posturas nacionalistas, que haviam caracterizado o período militar que antecedeu a ambos os governos. Imbuídos dos mesmos princípios e objetivos de aproximação e cooperação, os dois presidentes assinaram, em 11 de novembro de 1985, a Ata de Paz de Iguaçu, inaugurando com aquele ato o processo de integração que iria resultar mais tarde no Mercado Comum do Sul.

Ainda em 1986 os dois países declararam a disposição de avançar com o projeto, propondo a formação de um mercado comum binacional. Foi assinado então, em 29 de junho de 1986, o Programa de Integração e Cooperação entre a Argentina e o Brasil, ampliando, mais tarde, para um total de 24 protocolos de integração setorial. O Tratado de Integração, Cooperação e Desenvolvimento, firmado em 29 de novembro de 1988, estabeleceu que o mercado comum era uma meta a ser cumprida num prazo máximo de dez anos. O Tratado alterava assim o modelo de integração. Ele deixava de ser setorial para dar lugar a uma política de liberação comercial generalizada, mediante um sistema de desgravação tarifária automática, progressiva e linear.

A aproximação bilateral do Uruguai com a Argentina e com o Brasil já datava da década de 70. O Convênio Argentino-Uruguaio de Cooperação Econômica foi assinado em 20 de agosto de 1974 e o Protocolo de Expansão Comercial com o Brasil em 12 de junho de 1975.

A situação do Paraguai era mais sensível. No final dos anos 80 os três países do Cone Sul, Argentina, Brasil e Uruguai, já podiam comemorar o fim das ditaduras militares e o retorno dos governos civis, eleitos em processos democráticos. Porém, no Paraguai ainda mandava o general Alfredo Stroessner. Só após sua queda, em 3 de fevereiro de 1989, é que teve início um processo de aproximação daquele que seria o quarto sócio do Mercosul e que emprestaria sua capital, Assunção, para assinatura do Tratado do Mercado Comum do Sul, assinado finalmente em março de 1991.

O ano de 1991 foi usado quase todo para a ratificação do Tratado de Assunção por parte dos Parlamentos dos quatro "Estados Parte". O Mercosul entrou em vigor, na condição de uma associação entre governos, no dia 29 de novembro do mesmo ano. 


\section{Estrutura}

O Tratado de Assunção é um acordo firmado entre governos que não dá origem a estruturas interestatais. Todos os seus órgãos estão submetidos às autoridades governamentais dos Estados Parte e só decidem por comum acordo.

O Mercosul tem suas estruturas político-administrativas distribuídas em três níveis: de decisão, de execução e de consulta. O nível de decisão é formado pelo seu órgão máximo: o Conselho do Mercado Comum. Fazem parte do Conselho os ministros de relações exteriores e de economia. Pelo menos uma vez por ano o Conselho se reúne na presença dos quatro presidentes nacionais. A presidência do Conselho é exercida por um período de seis meses, segundo a ordem alfabética do nome dos Estados Parte. São da responsabilidade exclusiva do Conselho do Mercado Comum a condução política e a tomada de decisões superiores do Mercosul.

O órgão executivo é denominado Grupo Mercado Comum. Ele está formado por um titular e um suplente, representando respectivamente os Ministérios de Relações Exteriores, os Ministérios da Fazenda e os Bancos Centrais de cada Estado Parte. Em suas tarefas executivas o Grupo Mercado Comum, que tem atividade permanente, está apoiado por subgrupos de trabalho como, por exemplo, para assuntos comerciais, para normas técnicas, para política agrícola etc., responsáveis pelas políticas macroeconômicas e setoriais de suas respectivas áreas. A Comissão de Comércio do Mercosul, no caso, tem sob sua responsabilidade o acompanhamento da aplicação dos instrumentos da política comercial conjunta, seja no âmbito intrarregional, seja frente a terceiros países. A Comissão está formada por técnicos representantes de cada país e é coordenada pelas autoridades dos Ministérios de Relações Exteriores.

A Secretaria Administrativa do Mercosul tem sede permanente em Montevidéu. Ela é depositária de todos os diplomas oficiais e cuida ainda da rotina administrativa e das articulações entre as diversas instâncias do Mercosul. Além do seu corpo técnico, a Secretaria conta com representantes diplomáticos dos Estados Parte.

No plano consultivo atua a Comissão Parlamentar Conjunta, formada por 16 representantes parlamentares de cada Estado Parte, indicados por seus pares nacionais. Suas atividades intermitentes se limitam à formulação de propostas.

Ainda como estrutura anexa, complementar, o Protocolo de Brasília, de 17 de dezembro de 1991, criou um Sistema de Solução de Controvérsias com poder de arbitragem ad-hoc. Mais tarde, em 1992, foram estruturados ainda o Fórum do setor 
Privado do Mercosul e a Comissão Sindical do Mercosul, ambas de caráter consultivo, com a finalidade de cooperar com as atividades dos subgrupos de trabalho do Grupo Mercado Comum. O último a ser criado foi o Fórum Consultivo Econômico e Social. Ele está formado por nove membros, representando setores privados de cada país. Seu objetivo é assessorar as demais instâncias em questões econômicas e sociais, entre elas especialmente o Grupo Mercado Comum.

O fato dos órgãos do Mercosul terem um caráter inter-governamental mostra uma certa fragilidade, na medida em que suas ações ficam muito subordinadas aos governos nacionais dos Estados Parte. Esta falta de autonomia, embora bastante presente, no entanto, não impediu que o processo de integração avançasse, surpreendendo, por seu ritmo, até mesmo os mais céticos. As dificuldades encontradas não foram poucas, especialmente em decorrência da falta de autonomia nacional de cada Estado Parte na condução de suas políticas macroeconômicas e também em função das desproporções das respectivas economias nacionais entre si, em particular com relação à brasileira. A experiência mostrou, contudo, que com o diálogo político e técnico entre as partes diretamente interessadas os problemas foram sempre superados de forma suficiente para permitir fazer avançar o propósito da integração.

Na verdade, o teste mais sério para a sobrevivência do projeto de formação de um mercado comum e de integração entre os países do Cone Sul começa recém agora, quando a crise da economia internacional atinge o Brasil de forma direta e a nova política cambial brasileira ameaça a balança comercial entre o Brasil e a Argentina, principalmente. Se as contas externas da economia do Brasil se deteriorarem, a exemplo do que aconteceu com alguns países da Ásia, levando a uma desvalorização considerável do real e a uma recessão ainda muito mais grave do que a presente, as conseqüências sobre os parceiros do Mercosul serão inevitáveis. A tendência será então a de reações de proteção, como a ameaça da Argentina de atrelar sua economia ao dólar completamente, o que significa o mesmo que se retirar do processo de integração. Neste momento o Mercosul já está congelado e ameaça recuar. Resta aguardar para ver até onde ele resistirá às tensões a que será submetido nos próximos meses.

\section{Integração econômica}

O Mercado Comum do Sul, nos termos de sua própria definição - mercado comum - é um objetivo a ser alcançado pelo processo de integração entre os Estados Parte. Hoje os quatro países conseguiram estabelecer entre si, completa- 
mente, só uma área de preferência aduaneira, onde vigoram preferências tarifárias no comércio intrarregional. A zona de livre comércio ainda é imperfeita, uma vez que não foram eliminadas todas as tarifas e restrições. $\mathrm{O}$ mesmo pode ser dito da pretendida união aduaneira, como etapa a ser vencida em direção a um mercado comum. As tarifas externas comuns estão unificadas só em parte, persistindo várias exceções. A livre circulação de serviços e fatores, e até mesmo uma significativa harmonização de políticas econômicas, foram propósitos já manifestados pelos representantes governamentais e discutidos entre os atores sociais, incluindo-se aí os círculos acadêmicos. O processo é claramente imperfeito e carece de congruência interna, o que no entanto não impediu o ex-presidente Menem e outras autoridades argentinas a falarem várias vezes da hipótese do estabelecimento de uma moeda única para o Mercosul. A idéia pode parecer estranha, porém do lado brasileiro chegou-se a fazer um estudo técnico neste sentido, que aconselhou muito mais prudência do que precipitação. Dificuldades à parte, se se tivesse que medir o êxito do processo de integração do Mercosul pela variação ocorrida no comércio intrarregional, desde 1991, se teria que concluir que ele foi de enorme sucesso. Observou-se uma rápida abertura dos mercados intrarregionais, incluindo-se aí, os Estados associados Bolívia e Chile, e também para com terceiros países. O comércio interno do Mercosul cresceu a um ritmo (22\% anual) praticamente três vezes superior ao comércio com o resto do mundo entre 1992 e 1997 (7,3\% anual). ${ }^{2}$ A conseqüência de um tal desenvolvimento das relações dento do bloco foi um considerável desvio de comércio. Em 1996 o Mercosul foi responsável por mais de $46 \%$ do comércio total do Paraguai, mais de $42 \%$ do Uruguai, mais de $25 \%$ da Argentina e mais de $14 \%$ do Brasil. Os valores absolutos, em milhões de dólares, foram: para o Paraguai 635, para o Uruguai 1.186, para a Argentina 7.825 e para o Brasil 6.909. Outra consequiência é que o Brasil converteu-se no principal mercado para os produtos argentinos, absorvendo $28 \%$ de suas exportações, enquanto que a Argentina comprou $10 \%$ das exportações brasileiras. A abertura econômica dos países do Mercosul, acompanhada dos processos de privatização levados a cabo principalmente na Argentina e no Brasil, resultou em um substancial aumento dos investimentos externos diretos. Em 1996, 35\% do total dos investimentos na América Latina destinaram-se ao Mercosul. Os setores mais contemplados foram as telecomunicações, geração de energia, a indústria automotiva, a indústria química e os bancos, tanto públicos como privados. As inversões diretas não vêm só de

${ }^{2}$ Salvo indicações em contrário, todas as informações sobre o comércio do Mercosul foram tiradas das publicações do Instituto de Relações Europa - América Latina (Irela) de Madri, indicadas na bibliografia anexa. 
terceiros países mas igualmente de Estados Parte e associados, como o caso do Chile. Há uma visível preocupação dos capitais nacionais em melhorar suas posições dentro do mercado regional. Assim, é expressivo o número de empresas da argentina em solo brasileiro e também brasileiros na Argentina. As parcerias são freqüentes e se dirigem principalmente para o setor metal-mecânico. Os estoques de investimentos de parte a parte, acumulados pelos dois países, permite demonstrar uma posição de relativo destaque nas estatísticas nacionais respectivas nos últimos anos.

Entre os investidores de fora da região os Estados Unidos lideram com uma posição destacada, tendo acumulado 21,3 bilhões de dólares no período de 1990 a 1995, contra somente 7,9 bilhões de dólares do conjunto dos países membros da EU, no mesmo período.

Dentro da subregião sul-americana, o Mercosul também tem buscado parcerias, até com vistas a futuros processos de integração regional ampliada, que permita fazer frente a propostas como a da Área de Livre Comércio das Américas (Alca) levantadas pelos Estados Unidos.

Um exemplo, neste sentido, é o Chile. Convidado insistentemente a integrar o Mercosul em 1991, apesar das resistências iniciais da Argentina, o Chile preferiu não participar do bloco, alegando que suas tarifas externas médias (11\%) eram inferiores àquelas que seriam acordadas pelos Estados Parte por força do Tratado de Assunção. Por outro lado, o Chile não faz distinção de setores sensíveis, como ocorre no comércio externo do Mercosul. Entretanto, passado alguns anos e modificadas as condições internas e internacionais dos Estados Parte, ambos os lados voltaram a manifestar interesses em uma aproximação privilegiada. Em 22 de março de 1996 o Chile e os países do Mercosul levaram a público que em breve firmariam um acordo, que daria aos chilenos a condição de associados ao Mercosul. O interesse do Chile se deveu ao já significativo fluxo do comércio com todos os países do bloco, especialmente com a Argentina e com o Brasil. As intervenções diretas dos capitais chilenos nos quatro países também já eram bastante expressivas. Por sua vez, o Mercosul mostrava-se interessado no mercado chileno por suas características: um PIB per capita superior à média do Mercosul e em valor absoluto mais de três vezes a soma do Paraguai com o Uruguai. O Chile tem ainda conhecidos vínculos com os mercados da Ásia e do Pacífico.

Processo semelhante de aproximação do Mercosul com um terceiro país da região havia ocorrido pouco antes com o caso da Bolívia. Visando uma considerável redução de tarifas no comércio boliviano com os Estados Parte, que poderia 
chegar a 90\% das exportações daquele país para o Mercosul, ambas as partes firmaram um acordo de complementação econômica em 7 de dezembro de 1995. Desse modo a Bolívia passou a ser o primeiro país associado ao Mercosul. O objetivo maior é a concretização de uma zona de livre comércio entre as partes, a ser construída em um prazo de dez anos.

As associações do Chile e da Bolívia deram bons resultados. Os demais países, que juntamente com este último formam a Comunidade Andina, também têm buscado aproximação com o Mercosul. Assim, Venezuela, Colômbia, Equador e Perú iniciaram um processo de contatos bilaterais e multilaterais, o qual se intensificou particularmente em 1998, resultando na assinatura, em Buenos Aires, em 18 de abril, de um Acordo Marco entre aqueles quatro países e o Mercosul. Ele prevê o início de uma zona de livre comércio entre todos os participantes a partir de $1^{\circ}$ de janeiro de 2000 .

A aproximação da Comunidade Andina e o Mercosul tem um valor simbólico muito grande. De certo modo ela significa o resgate de um objetivo de quase quarenta anos, que retoma os propósitos da Associação Latino-Americana de Livre Comércio (Alalc) criada em 1960, transformada mais tarde, em 1980, em Associação Latino-Americana de Integração (Aladi). O entusiasmo dos negociadores em Buenos Aires foi muito grande, pois essa aproximação deixa o subcontinente sul-americano a um passo de uma Associação de Livre Comércio da América do Sul (Amercosul) para a qual, inclusive, já existe um segundo nome, ou seja, Associação de Livre Comércio Sul-Americano (Alcsa).

As reuniões realizadas em Montevidéu, no segundo semestre de 1998, mostram que as posições das duas partes ainda estão bastante distantes. Já há, em princípio, uma lista comum de produtos a serem beneficiados por margens de preferências tarifárias. O governo brasileiro, no entanto, entende que as propostas feitas pelos países da comunidade Andina ainda são muito bilaterais, quando deveriam ser multilateralizadas para contemplar todos os países participantes. Os andinos, por seu lado, consideram as ofertas do Mercosul muito tímidas. Citam como exemplo as várias propostas de margens de preferência tarifárias de $20 \%$, abaixo dos $28 \%$ concedidos por antigos acordos bilaterais firmados no âmbito da Aladi.

O ano de 1998 foi de tensões e atritos no comércio bilateral Argentina-Brasil mas também de importantes decisões para a liberalização e maior agilidade na circulação de mercadorias entre os seis países - os quatro do Mercosul mais a Bolívia e o Chile. Concretamente o Grupo Mercado Comum, o órgão executivo do Mercosul, deu início ao processo de reconhecimento da equivalência de controles de inspe- 
ção sanitária e fitosanitária do bloco. Em termos práticos isto significa a transferência da inspeção dos produtos para o país de origem, o que simplifica os trâmites alfandegários de importação. Da Argentina os principais produtos beneficiados serão a maçã e o trigo, e do Brasil as carnes de suínos e de aves.

Estas medidas, altamente desejadas, não serão, no entanto, de aplicação imediata para $100 \%$ dos casos. Há implicações administrativas e técnicas a serem observadas. Em primeiro lugar é necessário se chegar a um pleno acordo quanto ao padrão de inspeção e, a seguir, é indispensável que cada país disponha de recursos humanos e materiais para garantir a execução das inspeções nos níveis de qualidade acordados.

Pelo lado brasileiro as medidas adotadas apresentavam maiores dificuldades por estarem relacionadas ao código de defesa do consumidor, no caso, mais abrangente do que nos demais países. As diferenças, neste particular, foram objeto de intensas discussões ao longo do primeiro semestre de 1998. Em setembro foi possível se chegar a algumas conclusões. Entre elas destaca-se o propósito de que todo o bloco venha a adotar em breve um único código de defesa do consumidor. Enquanto isto não acontece, algumas medidas concretas devem se adotadas, como por exemplo a de proteção da saúde nos locais de trabalho e no sentido de prestação de assistência médica de emergência. Também devem ser combatidas as cláusulas abusivas nos contratos e a concorrência desleal. Outro ponto acordado foi a respeito da publicidade enganosa por um lado e, por outro, sobre a necessidade de informações indispensáveis à orientação dos consumidores. Conclui-se que a adoção de um código único não só protegerá o consumidor como melhorará as condições de circulação de mercadorias nos países do bloco.

\section{Integração funcional}

Desde sua origem, o Mercosul foi marcado por uma característica: de constituirse um acordo intergovernamental e não admitir nenhuma instância supranacional. Era uma forma de evitar o debate em torno da questão da soberania dos estados nacionais, tão cara à cultura histórica e política das sociedades locais em toda a região. Se os governos civis haviam podido abandonar tão rapidamente a xenofobia dos mandatários militares, nos anos 80, seria exigir mais do que o possível pretender partir imediatamente para um processo de integração que viesse a questionar, por pouco que fosse, a soberania nacional e a capacidade de decidir com absoluta autonomia sobre qualquer ordem de problemas, principalmente sobre a própria integração. 
Nesse contexto o Mercosul nasceu e se desenvolveu sem jamais por em questão um único ponto da soberania nacional dos Estados Parte. Pelo contrário, serviu muitas vezes como contraprova de que a soberania estava plenamente preservada. Quando surgiram problemas, se apostou no diálogo e na capacidade de negociação entre as partes. Quando os problemas foram mais graves se criou um Sistema de Solução de Controvérsias ad hoc ou então se indicou a adoção de arbitragem. A Câmara de Comércio Argentino-Brasileira lançou em maio de 1995 o centro de Conciliação e Arbitragem, valendo-se de uma convergência que situa muito próximas as legislações argentina e brasileira neste particular. $\mathrm{O}$ objetivo foi mais uma vez o de adiar a adoção de medidas que levem a criação de um tribunal supranacional.

Juristas, especialistas em direito público, reunidos na última semana de março de 1998 na cidade de Curitiba, no $1^{\circ}$ Congresso da Associação de Direito Público do Mercosul, entenderam, no entanto, ser urgente a criação de um Código Penal único para atender as demandas judiciais das partes integrantes do bloco. Propugnaram pela criação de um Tribunal Supranacional, observando que esse "Tribunal de Justiça do Mercosul" poderia ser viabilizado rapidamente, se assim estivessem de acordo os Ministérios da Justiça dos quatro países, pois ao contrário da experiência européia, no Mercosul as legislações são muito semelhantes e se apóiam em princípios básicos comuns.

A necessidade de uma integração mais afetiva no plano institucional-funcional não se dá só no plano dos Tribunais Superiores e dos Códigos. Um bom exemplo é a situação criada pela presença de um grande número de trabalhadores assalariados em atividades em países vizinhos, já que são mais de mil empresas em territórios estrangeiros, nos quatro países, por conta do processo de integração. Isto significa que, embora sem uma legislação específica para a circulação da força de trabalho, não é possível evitar que milhares de indivíduos se encontrem em efetiva atividade fora de território pátrio, em outro país do bloco. Não há uma legislação trabalhista comum e o Mercosul está longe disto. Acordos parciais, fragmentados, tentam ditar normas para os casos mais urgentes. Falta, no entanto, proteção efetiva à saúde, preceitos de segurança e garantias de previdência social comuns. O Fórum Consultivo Econômico Social do Mercosul tenta fazer a sua parte recomendando que os países ratifiquem as convenções da Organização Internacional do Trabalho, pois isto já ampliaria a base de legislação comum.

O Subgrupo sobre Trabalho, representando os quatro países do Mercosul e mais o Chile, reuniu-se em Brasília, no dia 17 de novembro de 1998. O SET-10, como foi chamado, preparou um documento -A Carta do Trabalhador-que foi examina- 
do, dois dias mais tarde, pelos cinco Ministros do Trabalho, reunidos no mesmo local. A intenção foi chegar a um acordo que permita preservar alguns direitos já conquistados pelos trabalhadores e que estejam assegurados nas legislações nacionais dos respectivos países. A reunião de Ministros lançou também o projeto do Observatório do Trabalho, que será um centro responsável pela geração de informações sobre o mercado de trabalho dentro do Mercosul e de seus países associados. Ele deverá permitir, tanto a empresários quanto a trabalhadores, um acesso facilitado a informações sobre o mercado de trabalho na região e sobre os programas oficiais e de iniciativa sindical voltados para a capacitação profissional.

A preocupação com a circulação de pessoas no Mercosul não está dirigida somente para trabalhadores, senão que também para profissionais liberais. Neste sentido, ministros e técnicos dos Ministérios da Educação dos seis países Mercosul mais a Bolívia e o Chile- estiveram reunidos no final de novembro de 1998 em Brasília para tratar da questão do reconhecimento mútuo de diplomas universitários.

Do encontro resultaram algumas decisões importantes, como a experiência que deverá começar com os cursos de agronomia, engenharia e medicina, considerados os mais importantes para o desenvolvimento da região. A primeira tarefa será o estudo de compatibilização de currículos mínimos a ser realizada por um grupo técnico formado por representantes dos seis países. O processo de abertura deverá ser cumprido num prazo de 10 anos e só estará plenamente em vigor após a concordância de todos os participantes. As condições válidas para um país deverão ser idênticas para os demais. Isto permitirá a livre circulação de profissionais liberais, dentro do bloco e de seus países associados, não só das três áreas prioritárias mas também das demais que a elas serão acrescidas.

Os ministros reunidos decidiram ainda criar um programa de estímulo à difusão das línguas portuguesa e espanhola. Para isto deverão apresentar, em breve, um projeto ao Banco Internacional de Desenvolvimento solicitando recursos para a formação de professores.

Se os juristas estão se encontrando agora recém pela primeira vez, as mulheres, através do Fórum de Mulheres do Mercusul, realizaram, em abril de 1998, o seu quarto encontro. Temas principais da reunião: preservação da paz internacional, igualdade de oportunidades em todos os setores da sociedade, preservação dos empregos, garantias sociais. O Mercosul deve contribuir para o alcance desses objetivos, sem o que perderia sua razão de ser. O Mercosul não é só uma questão econômica, concluiu o encontro, mas tem também objetivos políticos e sociais. 
De todas as reuniões realizadas ao longo do ano de 1998, talvez a mais importante tenha sido a $14^{\text {a }}$ Cúpula do Mercosul, que teve lugar em 24 de setembro, na cidade de Ushuaia, no extremo sul da Argentina. Ali se reuniram além dos quatro presidentes do Mercosul e mais os presidentes da Bolívia e do Chile, o presidente Nelson Mandela, da África do Sul, na qualidade de convidado especial. O resultado mais significativo do encontro foi o Protocolo Democrático de Ushuaia. Por esse documento torna-se obrigatória a cláusula democrática para os países integrantes do Mercosul ou a ele associados. A cláusula democrática determina que fica completamente vetada a participação no bloco de um país que viole a estabilidade institucional. Para passar a vigorar plenamente, no entanto, ela necessita primeiro da aprovação dos Parlamentos nacionais de todos os seis países.

Outras decisões importantes adotadas em Ushuaia foram relativas às compras governamentais. Ficou decidido que a partir do início de 1999 serão adotadas as primeiras regras comuns para compras realizadas por parte dos governos. Em outros termos, abrem-se à participação de todos os integrantes do bloco as licitações para a aquisição de materiais e equipamentos. Não foi definido no entanto se essa regra será válida só para os governos federais ou ainda para os estados, províncias e municípios.

Os acordos de Ushuaia trataram ainda de outro tema relevante, e já há algum tempo na mesa dos negociadores, ou seja, a questão dos serviços. Por acerto anterior havia sido estabelecido que todos serviços devem estar liberados dentro de um prazo máximo de 10 anos. Agora foram apresentadas e aprovadas as primeiras listas unificadas. O Brasil sugeriu a liberação imediata das áreas de farmácia e informática. O Paraguai e o Uruguai, conjuntamente, ofereceram a liberação nos serviços de telecomunicações. A Argentina não propôs nada, sob a alegação de que o seu mercado já é o mais aberto de todos e assim acolhe todas as sugestões. Os quatro países entenderam ainda que já podem liberar completamente todos os serviços nos setores de transporte e aqueles especializados das áreas de engenharia e arquitetura.

\section{O Mercosul e a UE}

O último acontecimento significativo nas relações entre o Mercosul e a União Européia foi a assinatura do Acordo Quadro Inter-Regional de Cooperação, que teve lugar em Madri, em 15 de dezembro de 1995. Desde então as relações entre as duas regiões foram morosas, rotineiras e sem novidades políticas dignas de destaque. 
Se observarmos o período compreendido entre 1990 e 1996 , constatamos que as relações comerciais entre o Mercosul e a UE apresentam o seguinte comportamento:

Tabela 1 : Intercâmbio comercial Mercosul - UE

\begin{tabular}{|l|c|c|}
\hline Ano & $\mathbf{1 9 9 0}$ & $\mathbf{1 9 9 6}$ \\
\hline Exportações Mercosul com destiono à UE & $31,9 \%$ & $23,4 \%$ \\
\hline Importações Mercosul com origem na UE & $23,5 \%$ & $29,1 \%$ \\
\hline
\end{tabular}

Considerando-se que os valores percentuais para os anos de 1997 e 1998 não variaram praticamente, se pode dizer que ao longo da década a União Européia foi o principal mercado comprador do Mercosul, ainda que com tendência de participação relativa decrescente. Enquanto fornecedor do Mercosul, a Europa dos 15 também esteve em primeiro lugar, só que, no caso, com uma tenência de participação relativa crescente.

A discrepância nas relações birregionais não está só nas tendência da participação relativas como comprador e fornecedor, nem ainda no fato de que o Mercosul, seja como exportador seja como importador, participar em menos de $2 \%$ do mercado comunitário. Há ainda a ser considerada a diferença da natureza das mercadorias que fluem e um outro sentido. Apenas 5\% das exportações do Mercosul para a UE representam máquinas e equipamentos, $3 \%$ são de transporte e mais $3 \%$ são produtos químicos. O resto está composto por produtos primários, de baixo valor agregado. Por sua vez a UE exporta basicamente máquinas e equipamentos (40\%) produtos químicos (17\%) e material de transporte (15\%).

Entre 1991 e 1995 o comércio total entre as duas regiões teve um aumento superior a $60 \%$. Esse crescimento, no entanto, refletiu muito mais o incremento das vendas da Comunidade. A Europa se beneficiou largamente da abertura das economias nacionais dos Estados Parte do Mercosul, especialmente a do Brasil e a da Argentina. Porém a reciproca não foi verdadeira. Por conta especialmente da política agrícola comum (PAC), mas também em função de outras restrições tarifárias e não tarifárias, o crescimento das exportações do Mercosul à União Européia, no mesmo período, foi de somente 4\%, enquanto que no sentido contrário chegou a $155 \%$. 
O caso do Brasil nos anos de 1994 e 1995 é paradigmático. A balança comercial brasileira com os 15 países comunitários registrou um saldo de US\$ 3,230 milhões em 1994. No ano seguinte, entretanto, a situação se inverteu e o déficit do Brasil chegou a US\$ 760 milhões.

Em junho deste ano, 1999, vai ter lugar na cidade do Rio de Janeiro a primeira conferência reunindo todos os chefes de Estado ou de Governo da União Européia, da América Latina e do Caribe. Será o encontro mais importante entre as três regiões realizado até aquela data. A agenda da reunião ainda está sendo preparada, mas já se sabe que alguns temas serão tratados e outros não. Entre os que serão tratados estão: o futuro diálogo político, que inclui os temas da democracia, dos direitos humanos, do controle do tráfego de drogas, da segurança, da integração regional, do desenvolvimento sustentável, do multilateralismo; as relações econômicas e a cooperação, onde estão subentendidos os problemas do sistema comercial multilateral, do crescimento e diversificação do comércio internacional, das inversões e fluxos financeiros, dos mecanismos para a cooperação técnica e de auxílio ao desenvolvimento; e por fim a cooperação cultural, o que significa dizer as questões da educação, da cooperação científica e técnica, das organizações não-governamentais (Eurolat 1998:7). A Conferência estará, sem dúvida, mais voltada para uma aproximação política, o que interessa às partes, pois no mínimo ela servirá para fazer frente à hegemonia norte-americana do mundo unipolar do pós-guerra fria.

\section{A crise}

O Mercosul nasceu num momento particular da trajetória dos países que o integram, já que todos faziam um esforço especial de superação dos efeitos negativos dos anos 80, quando atravessaram uma crise que ficou conhecida como a década perdida da história do desenvolvimento da América Latina. As dificuldades internas eram muitas e a economia mundial apresentava um quadro nada favorável.

A crise do México foi o primeiro grande desafio externo, superada sem conseqüências mais graves, ainda que, dentro do bloco, tenha tido algumas repercussões na economia argentina. Depois vieram as crises da Ásia e da Rússia. As ameaças sobre as economias do Mercosul ficaram então evidentes, em particular sobre a economia brasileira, por suas dimensões, sua abertura e sua exposição, face ao desequilíbrio de suas contas internas e externas. 
A continuidade do processo de integração dependeu sempre, e continua dependendo, de um patamar mínimo de convergência entre as economias do Brasil e da Argentina, responsáveis por mais de $95 \%$ da soma do PIB dos quatro países.

Por fim a crise chegou à região. Neste momento - janeiro de 1999 - a economia brasileira já abandonou o controle do câmbio do real frente ao dólar, que era uma das âncoras do plano nacional de estabilização econômica. A primeira consequiência interna ao Mercosul é a modificação dos termos da balança comercial entre o Brasil e a Argentina. As conseqüências, neste particular, podem ser desastrosas para o bloco e ainda para os países associados ao Mercosul, Bolívia e Chile. Fala-se já em revisão dos termos do comércio bilateral, e a Argentina, pela palavra de seu presidente, acrescenta mais um elemento conturbador, que seria a adoção do dólar americano como moeda nacional, de forma a proteger sua economia dos ataques especulativos internacionais.

Em outras palavras, não há dúvidas que a crise brasileira significa um duro golpe para Mercosul, tão grave que poderá até comprometê-lo definitivamente. O lamentável, se isto acontecer, é que os países da região estarão abandonado assim não um simples projeto de construção de uma zona de união aduaneira e de livre comércio, mas de integração política, de paz em suas fronteiras e de desenvolvimento de sociedades democrático.

\section{Bibliografia}

Barbosa, R. A. (1996). Comércio e negócios entre Brasil, Mercosul e União Européia. Revista Brasileira de Comércio Exterior. Rio de Janeiro, dez.

Eurolat (1998). Carta Informativa, 23, Celare, Santigo, out.-nov.

Fernández, R. e G. Gonzáles (1996). La coordinación de políticas macroeconômicas y el Mercosur. Contribuciones, Buenos Aires, 4: 93.

González, F. e F. Reca (1995). Tendencias actuales en las relaciones de la Unión Europea y América Latina. Documentos de Trabajo. Buenos Aires, fev.

Irela (1993). En Mercosur y la Comunidad Europea: una guía para la investigación. Documento de Trabajo. Madrid, 37.

Irela (1994). La Unión Europea en trasición y sus implicaciones para América Latina. Documento de Trabajo. Madrid, 39.

Irela (1994). La comperación europea hacia América Latina en los 90: una relevância en transición. Dossier. Madrid, 51, dez. 
Irela (1995). La nueva Europa y su impacto en América Latina. Dossier. Madrid, 53, mar.

Irela (1996). La Unión Europea y el Mercosur: hacia una nueva relación económica? Documento de Base. Madrid, jun.

Irela (1997). El Mercosur: perspectivas de un bloque emergente. Dossier. Madrid, 61, ago.

Irela (1998). La Unión Europea y el Grupo de Rio: la agenda regional. Documento de Base. Madrid, fev.

Irela (1998). América Latina y Europa más allá del año 2000. Dossier. Madrid, 65, set.

Markwald, R. (1997). Os fluxos do comércio entre Mercosul e União Européia. Revista Brasileira de Comércio Exterior. Rio de Janeiro, mar.

Senado de Buenos Aires (1996). El desafío del Mercosur. La Plata, maio.

Mercosul em números

\begin{tabular}{|l|c|c|c|c|}
\hline País & Uruguai & Paraguai & Argentina & Brasil \\
\hline PIB (US\$ milhões) & 19.959 & 10.029 & 320.000 & 769.000 \\
\hline PIB per capita (US\$) & 6.231 & 1.634 & 10.000 & 4.900 \\
\hline Inflação (\%, 12 meses até nov.) & 15,2 & 6,2 & 0,3 & 8,1 \\
\hline Salário Mínimo (US\$) & 95 & 250 & 150 & 112 \\
\hline IVA (\%)* & 23 & 10 & 21 & 0 \\
\hline Dívida Externa (US\$ milhões) & 5.250 & 1.475 & 108.000 & 188.200 \\
\hline \multicolumn{1}{|c|}{ Dados de 1997 } & & $*$ Imposto sobre valor agregado \\
\hline
\end{tabular}


Intercâmbio comercial (US\$ milhões)

\begin{tabular}{|l|c|c|c|c|}
\hline País & Uruguai & Paraguai & Argentina & Brasil \\
\hline Exportações ao Mercosul & 1.355 & 573 & 8.996 & 9.043 \\
\hline Total de Exportações & 2.730 & 1.196 & 25.359 & 52.986 \\
\hline Total de importações & 3.716 & 3.149 & 30.252 & 65.075 \\
\hline Saldo Comercial & -986 & -1.953 & -4.893 & -12.089 \\
\hline
\end{tabular}

Dados de 1998

O comércio dentro do Bloco (US\$ milhões)

\begin{tabular}{|l|c|c|c|c|}
\hline & Argentina & Brasil & Paraguai & Uruguai \\
\hline Argentina & - & 7.752 & 558 & 688 \\
\hline Brasil & 6.767 & - & 1.406 & 870 \\
\hline Paraguai & 106 & 443 & - & 24 \\
\hline Uruguai & 354 & 940 & 61 & - \\
\hline Total & 7.227 & 9.135 & 2.023 & 1.582 \\
\hline
\end{tabular}

Dados de 1997 